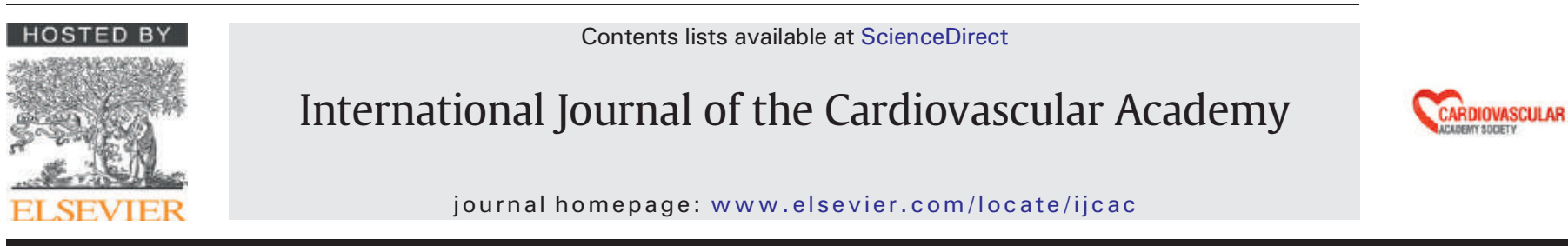

Case report

\title{
Myocardial reinfarction with simultaneous occlusions of two major coronary arteries one of which is due to the early stent thrombosis
}

\author{
Celal Kilit a,*, Taner Şen ${ }^{\mathrm{b}}$, Adnan Doğan ${ }^{\mathrm{a}}$, Basri Amasyalı ${ }^{\mathrm{a}}$, Mehmet Özgeyik ${ }^{\mathrm{a}}$ \\ a Department of Cardiology, Dumlupinar University, Faculty of Medicine, Kütahya, Turkey \\ b Department of Cardiology, Dumlupınar University, Kütahya Evliya Çelebi Training and Research Hospital, Kütahya, Turkey
}

\section{A R T I C L E I N F O}

\section{Article history:}

Received 23 November 2015

Received in revised form 20 January 2016

Accepted 22 January 2016

Available online 4 March 2016

\section{Keywords:}

Acute myocardial infarction

Simultaneous occlusion

Stent thrombosis

\begin{abstract}
A B S T R A C T
Coronary artery stent thrombosis is a rare but often fatal complication associated with percutaneous coronary intervention. Although strict adherence to dual anti-platelet therapy minimizes this risk, stent thrombosis will still occur in rare patients, leading to acute, subacute, or late life-threatening coronary syndromes. Intracoronary thrombosis is a usual finding in acute coronary syndrome but simultaneous formation of the thrombi in two different coronary arteries is very rare. Acute coronary syndrome is not simply the result of isolated local plaque disruption and thrombosis, but rather global coronary vessel inflammation, leading to weakening of atherosclerotic plaques in multiple sites nearly simultaneously. We report a case of myocardial reinfarction with simultaneous occlusion of two major coronary branches one of which is due to the early stent thrombosis.

(c) 2016 The Society of Cardiovascular Academy. Production and hosting by Elsevier B.V. All rights reserved. This is an open access article under the CC BY-NC-ND license (http://creativecommons.org/licenses/by-nc-nd/4.0/).
\end{abstract}

\section{Introduction}

Coronary atherosclerosis and thrombosis are major factors contributing to myocardial infarction. However, simultaneous formation of the thrombi in two different coronary arteries is very rare ${ }^{1}$. Patients with ST segment elevation myocardial infarction (STEMI) frequently have obstructive non-culprit lesions ${ }^{2}$. Stenoses in noninfarct arteries may cause serious adverse cardiac events that could be avoided by performing preventive percutaneous coronary intervention ( $\mathrm{PCI}$ ) during the initial procedure. In patients with STEMI and multivessel coronary artery disease undergoing infarct artery $\mathrm{PCI}$, preventive $\mathrm{PCI}$ in noninfarct coronary arteries with major stenoses significantly reduced the risk of adverse cardiovascular events, as compared with PCI limited to the infarct artery ${ }^{3}$. We report a case of myocardial reinfarction with simultaneous occlusion of two major coronary branches one of which is due to the early stent thrombosis. In our case, prior primary PCI for inferior STEMI has been limited to the right coronary artery (RCA) which is infarct artery, and preventive PCI has not been performed to significant stenosis in left circumflex artery (LCX).

\footnotetext{
* Corresponding author at: Dumlupınar University, Kütahya Evliya Çelebi Training and Research Hospital, 43050 Kütahya, Turkey. Tel.: +90 2742316660 4001; fax: +90 274 2316673.

E-mail addresses: ckilit@hotmail.com (C. Kilit), medicineman_tr@hotmail.com (T. Şen), doganadnan01@gmail.com (A. Doğan), dramasyali@yahoo.com (B. Amasyalı), mehmetozgeyik@gmail.com (M. Özgeyik).

Peer review under responsibility of The Society of Cardiovascular Academy.
}

\section{Case report}

A 69-year-old woman was admitted to emergency department with a sensation of tightness in the chest for $3 \mathrm{~h}$. She had a risk factor of hypercholesterolemia and no other coronary risk factors of smoking, diabetes, hypertension, or positive family history were documented. An electrocardiogram showed ST-segment elevation in leads DII, DIII and aVF (Fig. 1). She underwent cardiac catheterization and emergency angiography revealed significant stenosis in LCX and a total occlusion of RCA after the right ventricular branch (Fig. 2A, B). Left anterior descending artery showed no stenosis. The results of biochemistry laboratory at admission are as follows: Troponin I: $0.56 \mu \mathrm{g} / \mathrm{l}$ (normal range $0-0.023$ ), glucose: $177 \mathrm{mg} / \mathrm{dl}$, creatinine: $0.9 \mathrm{mg} / \mathrm{dl}$, HbA1c: $6.3 \%$, total cholesterol: $236 \mathrm{mg} / \mathrm{dl}$, triglyceride: $106 \mathrm{mg} / \mathrm{dl}$, low density lipoprotein cholesterol: $164 \mathrm{mg} / \mathrm{dl}$, high density lipoprotein cholesterol: $51 \mathrm{mg} / \mathrm{dl}$, hemoglobin: $12.2 \mathrm{~g} / \mathrm{dl}$, hematocrit: $36.9 \%$, and platelet: $333 \times 10^{3} / \mathrm{ml}$. Balloon angioplasty of the RCA lesion was performed and bare-metal stent was then employed to treat the lesion (Fig. 2C). For anticoagulation, unfractionated heparin was used during the procedure and the patient was loaded with clopidogrel $600 \mathrm{mg}$ orally. There were no complications and the patient tolerated the procedure well. Preventive PCI has not been performed to significant stenosis in LCX. After an uncomplicated 74-hours hospital course, she was discharged with acetylsalicylic acid, clopidogrel, atorvastatin, perindopril, and metoprolol treatment. Four days after discharge, the patient was admitted to the emergency department with chest pain similar to previous. The initial electrocardiogram demonstrated minimal ST elevation and $\mathrm{T}$ wave inversion in leads DII, DII and aVF (Fig. 3). The results of 


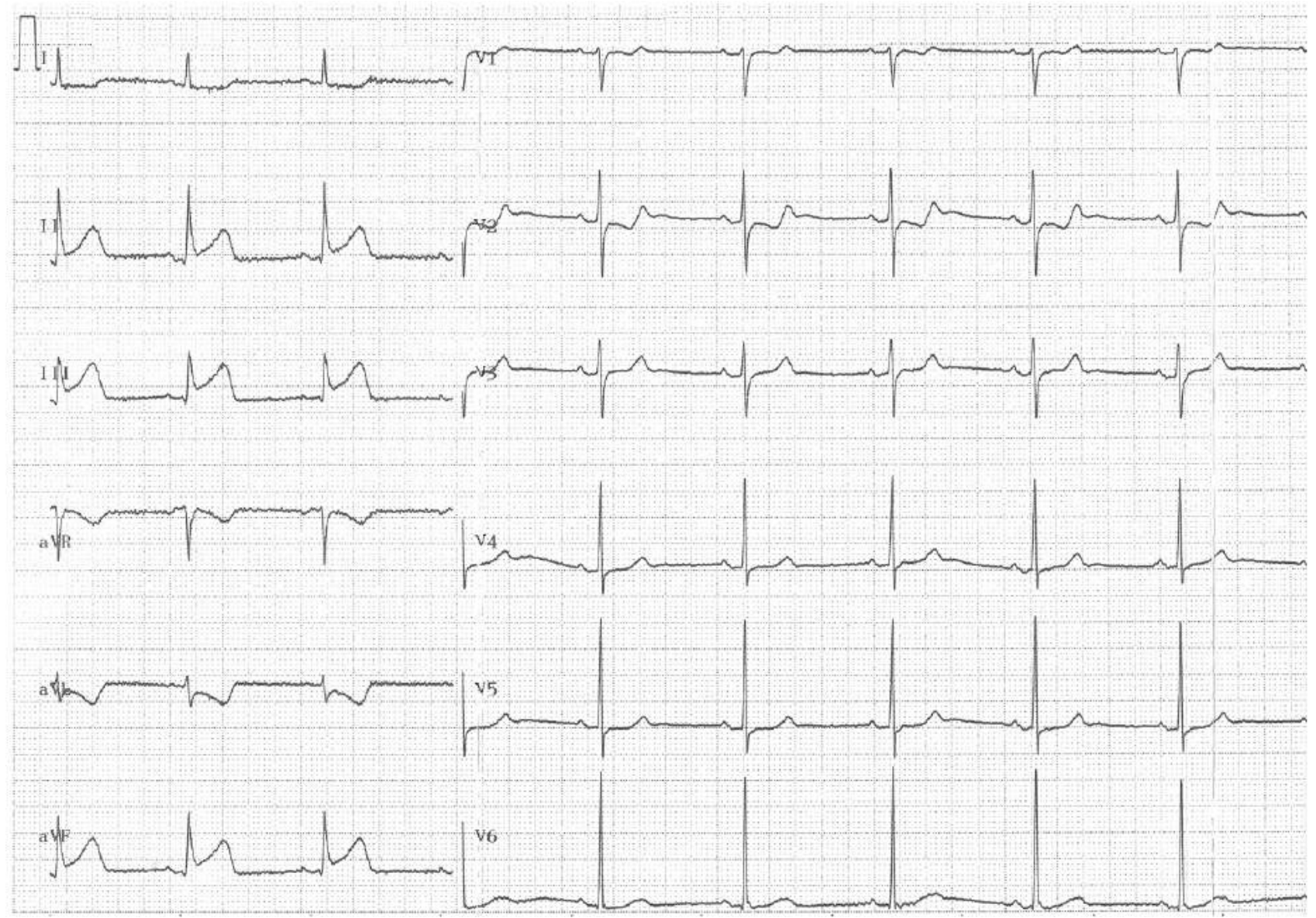

Fig. 1. ECG of the patient at first admission.

biochemistry laboratory at admission are as follows: Troponin I: $>80 \mu \mathrm{g} / \mathrm{l}$ (normal range 0-0.023), glucose: $132 \mathrm{mg} / \mathrm{dl}$, creatinine: $0.79 \mathrm{mg} / \mathrm{dl}$, hemoglobin: $11.6 \mathrm{~g} / \mathrm{dl}$, hematocrit: $35.2 \%$, and platelet: $370 \times 10^{3} / \mathrm{ml}$. She was adherent to dual antiplatelet therapy. The patient was diagnosed with myocardial reinfarction probably due to stent thrombosis. A slightly reduced response to clopidogrel (260 P2Y12 resistance units) was shown in platelet function test (target range for sufficient platelet inhibition, $<240$ P2Y12 resistance units). The platelet inhibition response to aspirin was sufficient. Stent thrombosis - at least partly - was thought to be due to slightly reduced response to clopidogrel. Therefore, the patient was loaded with ticagrelor $180 \mathrm{mg}$ orally before the procedure. Emergency angiography revealed a simultaneous total occlusion of the LCX and an in-stent total thrombotic occlusion of RCA (Fig. 4A, B). Stent in RCA showed no evidence of migration or malposition. The stent occlusion was treated with balloon angioplasty followed by a drug-eluting stent placed distal to the initial stent due to intimal dissection. The LCX occlusion was also treated with balloon angioplasty followed by an adjacent bare-metal stent. For anticoagulation, unfractionated heparin was used during the procedure. She was observed as an inpatient for 3 days and discharged with acetylsalicylic acid, ticagrelor, atorvastatin, perindopril and metoprolol treatment. Recent 1-year follow-up also revealed no significant symptoms and she has been compliant with her dual antiplatelet medication regimen.

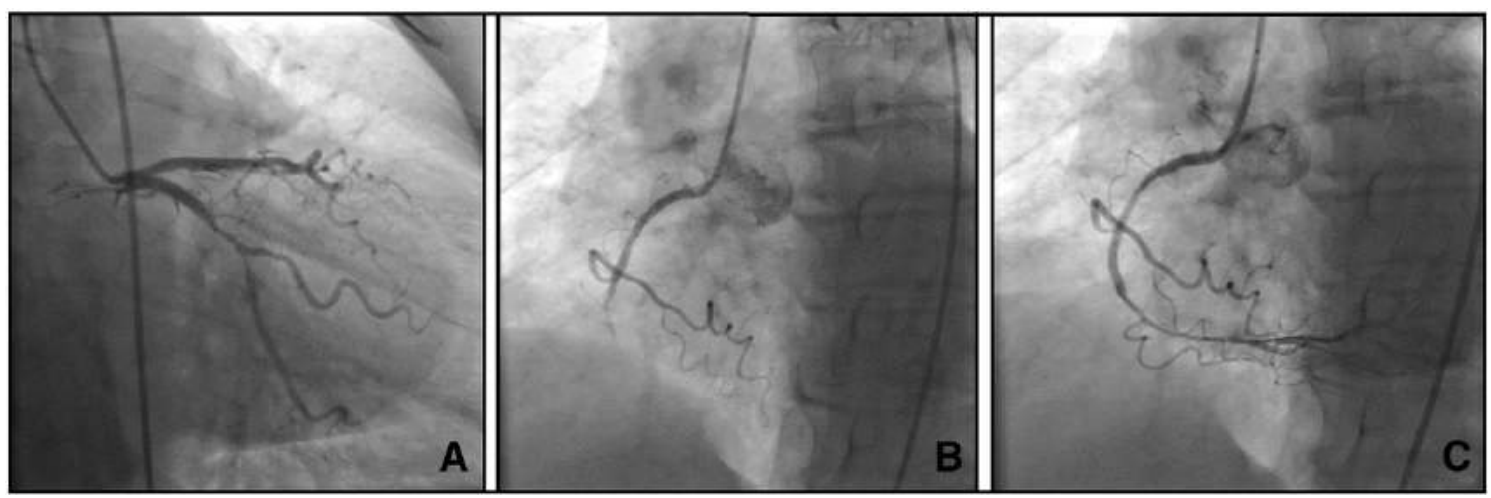

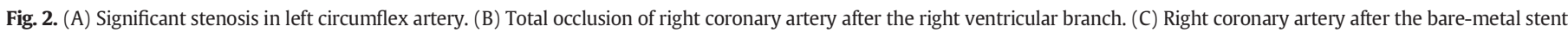
implantation. 


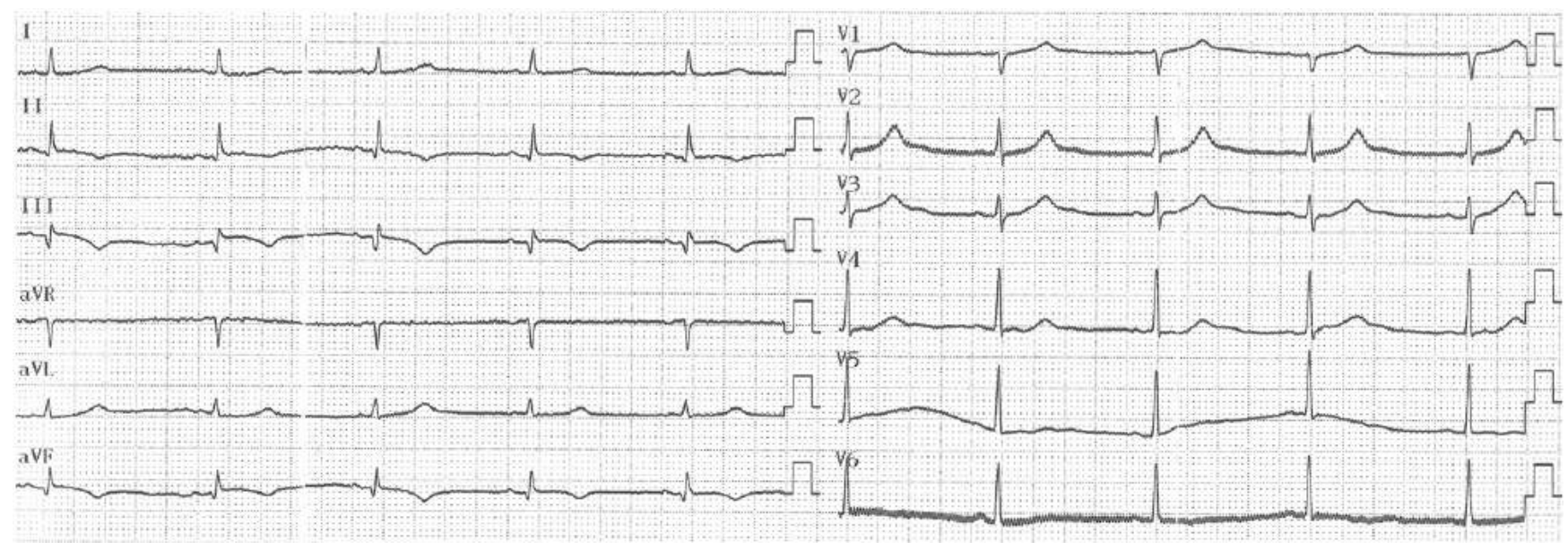

Fig. 3. ECG of the patient at second admission.

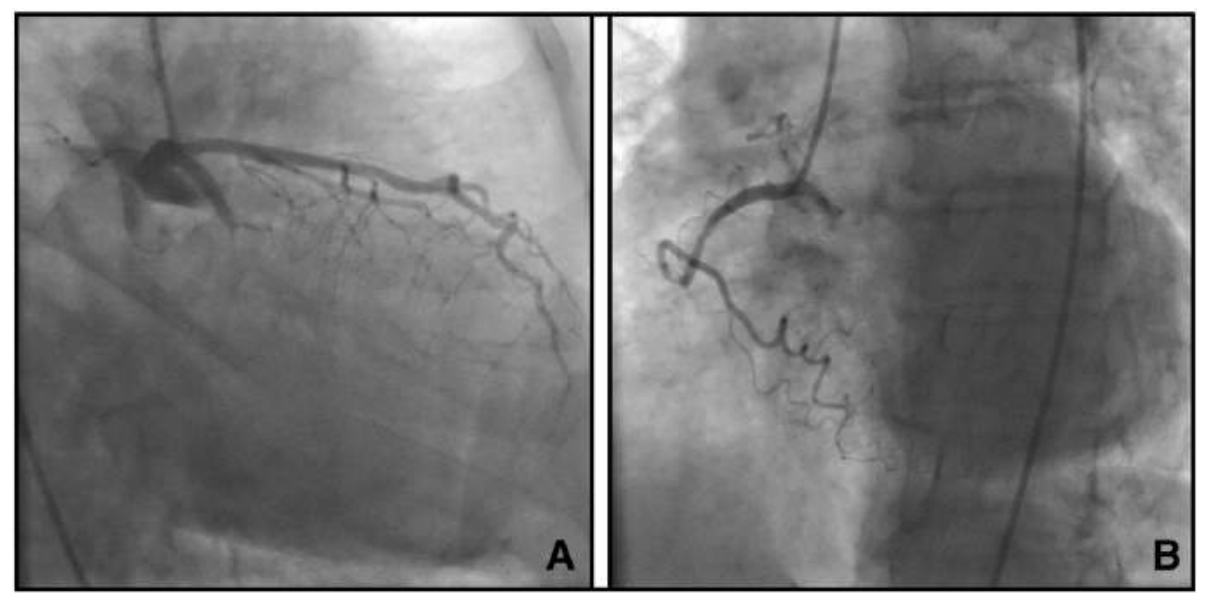

Fig. 4. (A) Total occlusion of left circumflex artery before large obtuse marginal branch. (B) In-stent total thrombotic occlusion of right coronary artery.

\section{Discussion}

About $40-50 \%$ of people presenting with STEMI have multivessel disease ${ }^{4,5}$. Patients with acute STEMI and multivessel coronary disease have a worse prognosis compared with individuals with single-vessel disease. Compared with those with single-vessel disease, patients with multivessel disease had a higher frequency of recurrent ischemia at 30 -days ${ }^{6}$. Also they have higher mortality rates and a greater incidence of non-fatal reinfarction ${ }^{6-8}$. It is unclear whether this is attributable to an increased disease burden or because relevant lesions in other areas are left untreated.

Coronary artery stent thrombosis is a rare but often fatal complication associated with PCI. Stent thrombosis can occur within days of stent placement (acute), up to 1 month post-procedure (subacute), or later (late). Although strict adherence to dual anti-platelet therapy minimizes this risk, stent thrombosis will still occur in rare patients, leading to acute, subacute, or late life-threatening acute coronary syndromes. Acute stent thrombosis is generally caused by the following mechanisms: antithrombotic drug resistance, hypercoagulable states, stent malposition/underdeployment, or coronary arterial damage during initial PCI like intimal dissection. The exact etiology of stent thrombosis, however, is often multi-factorial and difficult to comprehend.

Several studies have demonstrated the pathogenetic role of local thrombus formation in coronary arteries at the site of a ruptured plaque. Plaque disruption leads to platelet activation and to thrombin generation. Although intracoronary thrombosis is a usual finding in STEMI, simultaneous formation of the thrombi in two different coronary arteries is very rare. In our case, RCA was occluded by stent thrombosis and LCX was occluded by thrombus formation in significant stenotic lesion. The state of hypercoagulability and vasospasm caused by acute stent thrombosis may lead to thrombus formation and acute occlusion in LCX lesion. Atherosclerotic plaques in multiple sites may be weakened nearly simultaneously by global coronary vessel inflammation caused by acute coronary syndrome. Of course, the exact opposite is also possible. A new isolated local plaque disruption and thrombus formation in LCX lesion may have triggered the stent thrombosis in RCA via hypercoagulability. Inflammatory mediators in acute coronary syndromes could serve to facilitate a generalized multi-vessel prothrombotic state. Therefore, in patients with STEMI and multivessel coronary artery disease undergoing infarct artery PCI, preventive PCI in noninfarct coronary arteries with significant stenoses seems to be a rational approach.

\section{Conflicts of interest}

None. 


\section{References}

1. Nakagawa T, Yasuno $\mathrm{M}$, Tanahashi $\mathrm{H}$, et al. A case of acute myocardial infarction. intracoronary thrombosis in two major coronary arteries due to hormone therapy. Angiology 1994;45(5):333-338.

2. Goldstein JA, Demetriou D, Grines CL, Pica M, Shoukfeh M, O'Neill WW. Multiple complex coronary plaques in patients with acute myocardial infarction. $N$ Engl J Med 2000;343(13):915-922.

3. Wald DS, Morris JK, Wald NJ. et al.; Randomized trial of preventive angioplasty in myocardial infarction. N Engl J Med 2013;369(12):1115-1123.

4. Kelbaek H, Terkelsen CJ, Helqvist S, et al. Randomized comparison of distal protection versus conventional treatment in primary percutaneous coronary intervention: the drug elution and distal protection in ST-elevation myocardial infarction (DEDICATION) trial. J Am Coll Cardiol 2008;51(9):899-905.
5. Rasoul S, Ottervanger JP, de Boer MJ, et al. Zwolle Myocardial Infarction Study Group. predictors of 30-day and 1-year mortality after primary percutaneous coronary intervention for ST-elevation myocardial infarction. Coron Artery Dis 2009;20(6):415-421.

6. Sorajja P, Gersh BJ, Cox DA, et al. Impact of multivessel disease on reperfusion success and clinical outcomes in patients undergoing primary percutaneous coronary intervention for acute myocardial infarction. Eur Heart J 2007;28(14):1709-1716.

7. Halkin A, Singh M, Nikolsky E, et al. Prediction of mortality after primary percutaneous coronary intervention for acute myocardial infarction: the CADILLAC risk score. J Am Coll Cardiol 2005;45(9):1397-1405.

8. Muller DW, Topol EJ, Ellis SG, Sigmon KN, Lee K, Califf RM. Multivessel coronary artery disease: a key predictor of short-term prognosis after reperfusion therapy for acute myocardial infarction. Thrombolysis and angioplasty in Myocardial Infarction (TAMI) Study Group. Am Heart J 1991;121(4 Pt 1):1042-1049. 